\title{
The Role of Rationality in Social Science in Reference to Academic Dissertation and Thesis Preparation and Writing
}

\author{
Dr. S. B. M. Marume ${ }^{1}$, R. R. Jubenkanda ${ }^{2}$, C. W. Namusi ${ }^{3}$ \\ ${ }^{1}$ BA, Hons BA, MA, Madmin, Msoc Sc, PhD \\ ${ }^{2} \mathrm{BSc}, \mathrm{MSc}, \mathrm{MSc}$ Econ, DPhil Candidate \\ ${ }^{3}$ Badmin (Hon), MPA, DPhil Candidate
}

\begin{abstract}
Scholars of all academic disciplines and persuasions are systematic research studies on selected topics in their own an area of specializations and study and to present their research works in a scientific manner. This means the research work should be meaningful. In all essence the research presentation must be:
\end{abstract}

Keywords: rationality, meaningfulness, coherence, universality and generality

\section{Introduction}

The purpose of this article is to define, explain and demonstrate what rationality means; its bases; and its central place and role in academic dissertation and thesis preparation, writing and presentation.

\section{Characteristics of Philosophical Thought}

\subsection{What is Rationality?}

Philosophy is sometimes designated as rational. The question immediately arises as to: what do we mean by saying that philosophy is sometimes designated as rational? The philosopher aims at gaining knowledge. When he/she has gained knowledge he/she will understand and will be able to view reality in correct perspective. It needs to be understood that rationality is a characteristic of philosophical systems. It is usually associated with knowledge. There are certain conditions with which a given statement must comply to be rational.

These conditions are criteria or standards upon which we base our arguments for accepting or rejecting knowledge. When he/she has gained knowledge he/she will understand and will be able to view reality in correct perspective. It needs to be understood that rationalityy is a characteristic of philosophical systems. It is usually associated with knowledge. There are certain with which a given statement must comply to be rational. These conditions are criteria or standards upon which we base our arguments for accepting or rejecting a given statement as depicting knowledge or non-knowledge.

\section{Certain conditions}

Two conditions must constitute requirements for rationality:

(a) Meaningfulness and (b) basis for assertion.

(a) Meaningfulness or intelligibility
Firstly, a given statement is rational if it is meaningful or intelligible. It must satisfy logical requirements relating single statements and also to the relation between statements. A statement is rational when it is compatible with already existing rational statements. It will then be easy to establish the interconnectedness between it and the other statements. The meaningfulness or intelligibility of a statement is established if each of the components or elements of that statement is recognizable. Furthermore, the components or elements must form a unity. This means that each component or element stands in a special relationship to other elements. This special relationship must reveal unity and coherence. Here is an example of a statement:

"Man fat this is." In this we are a string of words which do not stand in a special way. These words do not express a meaningful or intelligible statement since they are not united. But the statement: "This man is fat," is a rational statement. The rules of English grammar have been observed. One of the components must not exclude another. Therefore, the coupling of the components must not be contradictory. For instance, we cannot say that "the fat man is thin." A man cannot be fat and thin at the same time. Such a state of affairs is contradictory and, therefore illogical. From the above examples, a host of complementary terms and concepts to the term rationality have emerged; namely: meaningfulness, intelligibility, compatibility, interconnectedness, special relationship, unity, coherence, recognizability, no exclusion, and no contradiction. Therefore, a statement must satisfy logical requirements relating single statements and also to the relation between statements.

\section{(b) Grounds for assertion}

Secondly, we say a statement is rational if there is a basis for its assertion. A given statement expresses a definite state of affairs. For an example, "The man is fat." When we say "the man if fat," we are in effect expressing a definite state of affairs. Because of this it is necessary to distinguish from wishes, questions or commands. If we say "we wish we were rich," it means that we are not rich. 
We are merely wishing but the state of affairs we want does not exist. Similarly, questions and commands do not express an existing state of affairs.

The point is registered that a statement is rational if there is a basis for its assertion. In other words, a given statement expresses a definite state of affairs. In the words of Arnold Brecht [1967: 48-54], rationality demands fact, truth, reality and proof.

\section{Cases of irrationality}

The point at issue is not the base form but rather the purpose of expression as depicted in the structure of the statement itself. To account that real knowledge is difficult to come by we must make an analysis of irrational thinking. Let us consider the example of a university or college undergraduate. Let us say for the sake of arguments, he/she has been studying hard and has been making good grades in he/she assignments. Now he/she has a dream. In the dream, he/she dreams failing the examinations lamentably. The following morning he/she tells his/her colleagues about the dream. Let us say our dreamer now does not see the value of a consistent study and revision even though his/her colleagues advise him/her not to take the dream seriously.

$\mathrm{He} / \mathrm{she}$ writes the examination. He/she fails. He/she tells his/her colleagues: "My dream has come true!" This is in point of fact false prophesy. After the dream, the person created the conditions under which the prophesy could be fulfilled.

The philosopher or researcher thinks rationally. He/she tries to think rationally. He/she takes care that there are grounds for his/her contentions. Logical thinking is not a characteristic peculiar to philosophy alone. Sciences, for instance, psychology, sociology, political science, economics, public administration, strategic management and so on, too are characterized by logical thinking. Each and every science has its own methods. These methods must be reliable and valid. So when we use the term rationality our accent is on method. When the accent is on the problem, we use the term universality. In summary on the concept of rationality we say that the philosopher strives for understanding. When he/she understands, he/she increases the stock of his/her knowledge and he/she thereby deepens his/her experience. This immediately brings in the point which all special scientists must not lose sight of in all their scientific research endeavors that: in the process of human knowledge there is the human reason and capacity of an for thought, that is, rationalism, on the one hand, and, on the other hand, there is empiricism which conveys to us the sense impressions of the world around us. These two [rationalism and empiricism] process all the sense impressions of the world around us systematically transforming them into systems of knowledge.

\subsection{Universality}

In respect of the concept of universality in research endeavors, we usually speak of two most important terms and concepts, namely, comprehensiveness and generality.

\subsubsection{Comprehensiveness}

We as academics and researchers, call something comprehensive when it includes all components or parts. When we say philosophy attempts to construct a world view we thereby demonstrate the comprehensiveness of the discipline. In sciences, for instance, political science, economics, business administration, public administration, strategic management, sociology, psychology and so on, each separate science studies one particular aspect of empirical reality; in philosophy, we pose questions about reality as a whole without intentionally concentrating on just one particular aspect of reality. A physical object can be comprehensive, for an example, in that it possesses all its parts. However, an object is always particular.

\subsubsection{Generality}

But a theory or principle can very well be general. In stating that philosophy is general, we mean it seeks to find out the general basis of something (some phenomenon). Let us take the case of knowledge as an example.

(a) Epistemology, that is, the theory of knowledge - one of the identifiable branches of philosophy - endevours to determine what knowledge is. It does not attempt to analyze this or that sort of knowledge; it attempts to find out the general characteristics of all knowledge.

(b) Philosophy of science: Let us take science as another example. There are many particular sciences. One branch of philosophy examines the characteristics of an conditions for any science - it studies the idea of ,scientificness. "This branch is called the philosophy of science.

(c) Formal logic: Another case is that of deduction or reasoning itself. There is no science in which we do not make deductions. From one given number of statements. Formal logic is the study of the general conditions or rules involved in all deductions. The logician enquires what a rule is and what function it fulfils. Logic serves a general function in that it investigates the general suppositions underlying all scientific operations such as inferences.

(d) Symbol - system of philosophy

In the sense that philosophy is a general science or a science of principles, we may state that the philosopher distinguishes between ,objects studied by the sciences' and ,statements made about these objects." The philosopher poses questions concerning the statements made about objects. The philosopher poses a series of questions concerning the purposes, aims, objectives, means and suppositions reflected in a ,system of knowledge about objects. " For this reason we must distinguish two ,symbolic levels." The language of science or its ,symbol-system, "lies at a different level from the symbol-system of philosophy.

\subsection{Synoptic analysis of rationalism and empiricism}

If the view that a system of knowledge is about by rationalism, on the one hand, and, on the other hand, by empiricism; then it becomes only too sensible to examine briefly the fundamental of these bases of our systems of knowledge. 


\subsubsection{Rationalism}

Etymologically, the ,ratio ${ }^{\text {ee }}$ means ,the understandingee or simply reason. Remembering that the understanding is regarded above all as the logical capacity of human being, it is quite clear that rationalism advances the view that knowledge is mainly a product of the labours of human thought performed by reasoning. This means that knowledge must have the characteristics of: (a) necessity and (b) general validity.

\section{The fundamental thesis of rationalism}

The fundamental thesis of rationalism is that the true being is not catered for by the evidence of the senses, but by pure thought, of which logic is an example, and which, in its purest form, is embodied in mathematics. Rationalism is preoccupied with conceptual schemes, constructions and logical manipulations. Rationalists offer the following arguments to support their approach to the fundamental thesis of rationalism that:

(a) Logical and mathematical knowledge is not subject to the illusions of the human senses. It is in philosophy that objectivity eliminated from the bondage of the illusions of the senses can be attained.

(b) Results of logical and mathematical analyses are universal and externally valid: they are not subject to change; they are invariable. For example, $4+2=6 ; 3 \times 9$ $=27$; the sum of the angles of a triangle equals $180^{\circ}$, and 30 minus $4=26$. The results will not change. They are also universally valid. We, therefore, speak of the invariability, the unchangeability of logical and mathematical knowledge.

(c) The only observations that are exact and valid are those that can be formulated in mathematical terms as measurements and counting results. For example, three metres, 10 kilometres, 6 kilograms. This measurement is exact and valid. Again the numbers 11, 12, 27, 29, 75, 101, 194, etc are exact counting results. They are unchangeable, universally valid, and exact.

(d) Two interpretations of rationalism: there are, however, two interpretations of the rationalistic view, namely, radical rationalism and critical rationalism.

(i) Radical rationalism: advances that only pure reason can understand the true being and the world process of which mathematical knowledge forms the purest form of knowledge. Therefore, we say that radical rationalism is the theory that construction attained through thought, logical reasoning and purest conceptual analysis the only valid knowledge.

(ii) Critical rationalism: in critical rationalism a rational idea is deduced but this idea is regarded as an hypothesis which has to be tested and rejected if it does not stand the empirical test. Critical rationalism accepts that there are also other sources of knowledge.

(e) In conclusion: rationalism, therefore, in its extreme (radical) form is rejected because it asserts that only pure reason can understand the true being and the world process. It totally ignores the possibility of knowledge being brought by other sources.

(f) Articulate rationalists include:

\subsubsection{Empiricism}

Empiricism is a theory about the grounds of our knowledge of reality. The central thought is that the only source or ground of such knowledge is our experience. No knowledge therefore with existential reference is possible independently of experience. The data from which our knowledge is constructed stem from the empirical observations. There are, however, two interpretations of the empiricistic view. These are radical empiricism and critical empiricism.

\section{(a) Radical Empiricism}

Radical empiricism contends that all our concepts and knowledge are reducible to date of our empirical observation. Radical empiricism accepts the fact thaty all knowledge is of an hypothetical nature because each subsequent observation modifies a preceding observation. There is no reason why a given statement must be necessary and generally valid. The empiricist cannot appeal to principles like the uniformity of nature because such principles cannot be verified by means of empirical observation.

\section{(b) Critical Empiricism}

In critical empiricism, it is maintained that only our knowledge of the empirical world is founded upon experience. It is allowed that there are also statements which are accepted as knowledge by virtue of the logical form, but it is argued that such statements tell us nothing about the world. They tell us only how particular words are employed in certain contexts.

Whilst empiricism is in its extreme form is rejected, it must be granted that it is difficult to understand how we can acquire knowledge of the world without empirical observation. The enormous progress made by the natural sciences would seem to bear out the empiricists adage: if you want to know nature, go out and investigate it.

\section{(c) Great empiricist forerunners}

Some of the great empiricist forerunners are: Sir Francis Bacon [1561-1626]; John Locke [1632-1714]; and D. Hume [1711-1776], whilst the positivists stressed the importance of the theory.

\section{Conclusion}

Whatever happens, it is highly urged of dissertation and thesis candidates to note that academic research studies and presentations be characterized by rationality and backed by empirical observation. Thus, in the process of human knowledge there is the human reason and the capacity for thought, that is, rationality (rationalism), on the one hand, and on the other hand, there is empiricism which conveys to us the sense impressions of the world around us. These two [rationalism and empiricism] process all the sense impressions of the world around us systematically transforming them into systems of knowledge.

\section{References}

[1] J. Ayer: Language, truth and logic: $2^{\text {nd }}$ edition: New York: Dover Publications, 1946. 
[2] Arnold Brecht: Political Theory: The Foundations of Twentieth - Century Political Thought: Princeton: New Jersey: Princeton University Press, 1967.

[3] J.J.N. Cloete: Introduction to Public Administration: Pretoria: J. L. Van Schaik, 1985.

[4] F. Dinkines: Introduction to Mathematical Logic: New York Appleton - Centrury - Crofts, 1964.

[5] S.B.M. Marume: Public Administration: special contemporary problems and challenges: LAP Lambert Academic Publishing, 2015 [ISBN: 978-3-659-75883-6].

\section{Author Profile}

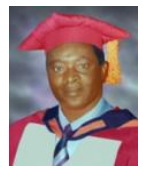

Samson Brown Muchineripi Marume: born on 15 July 1943; a former senior civil servant for 37 years and deputy permanent secretary; ten years as a large commercial former; well travelled domestically, regionally $[\mathrm{SADC}$ countries and Africaes Kenya, Ethiopia, Sudan, Libya, Uganda]; and internationally [Washington, New York and California in USA; Dublin and Cork in Ireland; Netherlands, France, former Yugoslavia Belgrade; Rome and Turin in Italy; Cyprus - Nicosia; Athens - Greece; Beijing - China; Singapore; Hong Kong; Japan; and UK]; six years as management consultant and part - time lecturer and $\mathrm{PhD} / \mathrm{DPhil}$ thesis supervisor, internal and external examiner; researcher and writer and currently senior lecturer and acting chairperson of Department of Public Administration in Faculty of Commerce and Law of Zimbabwe Open University; is a graduate BA, special Hons BA, MA [Public Administration] [Unisa, South Africa], MAdmin magna cum laude in transport economics, MSoc Sc cum laude in international politics, $\mathrm{PhD}$ summa cum laude in public administration [CUAS, California, United States of America].

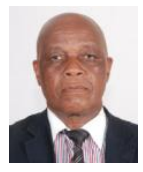

Roy Robson Jubenkanda: 2008, DPhil (Currently pursuing DPhil pursuing DPhil studies with (ZOU); 2000, MSc in Strategic Management - University of Derby, U. K; MSc. Econ. In international Economics, Banking and Finance- University of Wales, Cardiff College of Business Studies, U.K.; 1983, BSc (Hons) Degree in Economics - University of Zimbabwe, Zimbabwe; 1976 Business Studies Diploma - Solusi University, Zimbabwe; 2005, Certificate in Distance Education Practitioner (UNISA); 2011, Certificate in Higher Education Management in Southern Africa (University of the Witwatersrand) Johannesburg, South Africa.

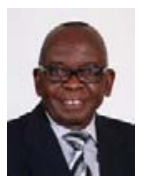

Cornelius Wonder Namusi: current studies: DPhil (candidate) in Public Administration; 1991, Master of Public Administration (UZ); 1982, Bachelor of Administration Honours (UZ); 2011, Certificate: Module Writing; 2011, Certificate: Managing the training programme - ESAMI, Tanzania; 1990, Certificate advanced work study (Canada); 1986, Certificate: Organisation and methods O \& M), Institute of Development Administration IDM Botswana); 1983, Certificate in Labour Administration, African Regional Labour Administration Centre (ARLAC) (Nairobi); 1964, Primary Teachers Higher Certificate (PHT) Waddilove Teacher Training Institution, Marondera, Zimbabwe 